\title{
A review on machining of metal matrix composites using nanoparticle mixed dielectric in electro-discharge machining
}

\author{
Shalini Mohanty and B.C. Routara* \\ School of Mechanical Engineering, KIIT University, \\ Bhubaneswar-751024, Odisha, India \\ *Email: bcroutray@gmail.com \\ Phone: 91-9438317760
}

\begin{abstract}
The growth in the new advanced materials that are harder till date have led to the improvement of technologies used to machine them. Nowadays, new materials have been developed to be used in different sectors where lighter and harder materials are in vast requirement. Moreover, materials machined with high precision machine tools have to provide the greatest surface finish such that it catches the pace with other competitive materials. Research has shown that the electro-discharge machining (EDM) is the only machine tool that has created history in machining hard materials. In the recent years, metal matrix composites (MMCs) have an increasing demand in the industries since they are hard materials to machine and a good finish is required in the aerospace, marine, aircraft, nuclear and other similar industries. Thus, EDM has gained fame in machining MMCs. With due course, the powder mixed electro-discharge machining (PMEDM) has created efficient EDM, with the use of powders in the dielectric. The dielectric mixed EDM has been used for efficient material removal rate (MRR). With the change in technologies, the sizes of powders that have to be added in the dielectric fluid go on decreasing. In this review, studies by numerous researchers on the MMCs that are machined with the use of PMEDM are mentioned. The powders used in the experimentation are of nano size. Furthermore, the optimization technique used by the researchers is discussed in the present study.
\end{abstract}

Keywords: Electrical discharge machining, metal matrix composite, powder mixed dielectric, nanoparticle

\section{INTRODUCTION}

In the age of advanced materials like nano-materials, super alloys, ceramics and metal matrix composites, the need of machining the same materials has challenged many researchers in the era of modern machining [1]. These materials find their place in the hard and difficult to cut machine category, requiring high precision and better surface quality pertaining to the higher machining cost. The properties include high strength, high flexural strength, good damping capacity, minimum thermal expansion and desirable fatigue characteristics. To meet the challenges of machining these advanced materials, precision engineering with better surface finish has to be implemented. The thermal, mechanical, chemical and electro-magnetic properties of these advanced materials have failed the conventional machines [2]. On the other hand, the non-conventional machining is gaining speed in the modern manufacturing industries to establish its name and fame 
and obtain improved surface finish and minimal machining cost in case of advanced materials [3]. One such non-conventional machining process is the electro-discharge machining $(\mathrm{EDM})$ which is gaining popularity in machining these difficult machine materials with complex shapes. In this process, the material is removed by erosion through a series of continuously electrical sparks between the tool and work piece. The heat or thermal energy developed between the interface cause the melting and vaporization of work piece material. Sometimes the obtained poor surface finish and machining efficiency restricts the application. To superimpose this problem, the EDM with powder mixed dielectric was used [4]. The spark gap had to be increased by adding up powders in the dielectric fluid so as to reduce the insulating strength, thereby making the process more stable than before and improving the material removal rate (MRR) and surface finish (SF) [5-8].

Continuous advancement has led to the use of more and more composite materials [9-11]. The most used are the metal matrix composites (MMCs). The importance of composite is revealed by the truth that it is widely used for all sorts of industrial applications [12-14]. The difficulty in machining by EDM over a MMC has been sorted out by the use of powder mixed dielectric EDM (PMEDM). The powders that are used till date are aluminium, graphite, copper, chromium, silicon carbide, etc.[15]. The use of powder enhances the EDM process which includes the increase in MRR and improves the surface quality. With the improvement of nanotechnology, nanoparticles were introduced in the EDM dielectric fluid to improve yet more surface quality and hence eliminating micro-cracks. Moreover, the suspension of nanoparticles produces a high sparking gap [15]. Factors such as particle size, density and concentrations, electrical resistivity and thermal conductivity of powder sustain effectively in improving the surface quality of the EDM processes [16]. With the use of nano-sized powders, the suspended $\mathrm{SiC}$ and $\mathrm{Al}_{2} \mathrm{O}_{3}$ in the dielectric medium will affect the surface properties. The average reduction in the surface roughness was observed to be ranging between $14 \%$ and $24 \%$ less as compared to the pure dielectric [17]. The optimisation of various process parameters will yield to the emergence of better surface finish with better MRR and other characteristic properties. In the present work, a study was carried out related to fabricating the different types of MMCs and effect of nano powder mixed dielectric in the EDM process. The utilization of optimization processes upon various process parameters was studied.

\section{METAL MATRIX COMPOSITE}

Metal matrix composite includes the matrix as a metal or an alloy, giving high strength to it. The use of various MMCs is due to the fact that it possesses low density, good fatigue response and high strength, specific modulus, thermal conductivity, abrasion resistance, vacuum environmental resistance and wears resistance [9, 14, 18-20]. Since they are difficult to machine using the conventional way, a non-traditional way has been adopted to machine them. EDM being a thermal material removal process is widely used in machining these advanced materials [2]. MMC being machined under EDM has created a benchmark in the field of research. Researchers nowadays are taking interests into advanced materials for the development of yet more advanced products, equipment or accessories for the current generation [1]. The matrix phase in MMCs serves as the load transferring and distributing elements upon the reinforcement or dispersed phase. The load transfer mainly depends on the type of matrix, bonding between the matrix and reinforcement, type of reinforcement and fabrication technique to manufacture the MMC 
[21]. The MMCs are mainly classified as the continuously reinforced composites and discontinuously reinforced composites. The continuously reinforced composite comprises long fibres or filaments whereas the discontinuously reinforcement composite constitutes short fibres, whiskers or particles. The properties and behaviour of the matrix material should be as such that it should match the requirements of the reinforcement. Being the primary constituent, the matrix should be chosen with due care so that its chemical attributes should be compatible with that of the reinforcement, pertaining to its own behavioural characteristic properties [22, 23]. Taya and Arsenault [24] suggested many matrix material types such as $\mathrm{Al}, \mathrm{Cu}, \mathrm{Pb}, \mathrm{Mn}, \mathrm{Ti}, \mathrm{Ni}, \mathrm{Mg}, \mathrm{Fe}, \mathrm{Ti}, \mathrm{Si}, \mathrm{Zn}, \mathrm{Ag}$, etc. on account of corrosion resistance and oxidation properties. Most widely available and used metal alloys are aluminium and titanium. Aluminium fulfilling all the requirements of a good matrix is the best suitably used matrix material [25]. It means it has low density, good fatigue response, and high strength, specific modulus, thermal conductivity, abrasion resistance, vacuum environmental resistance and wears resistance [18] making it best fit for matrix material.

The reinforcement provides strength, stiffness, and temperature resistance capacity, hence lowering the density of MMC. Its characterization is done on the basis of its shape, dimensions, volume fraction, chemical composition and distribution of the matrix [24]. With the use of fibres as the reinforcing material, the anisotropic behaviour of fibre reinforced matrix has been observed. The most commonly used reinforcement elements include $\mathrm{Al}_{2} \mathrm{O}_{3}, \mathrm{TiB}_{2}, \mathrm{SiC}$, graphite, Thorium and Boron. Graphite reinforcement gives high thermal conductive composites with good mechanical properties and high damping coefficients at increasing temperatures [26]. Aluminium reinforcement gives dry properties, and cavity formation upon graphite oxidation leading to manufacturing difficulty, and hence high temperature suitability is denied for these elements [25]. The increased tensile strength, hardness and wear resistance of Aluminium MMC is obtained by the use of Alumina, $\mathrm{TiO}_{2}$, oxides of others, etc., as reinforcements [27]. On the other hand, Silicon Carbide ceramics shows excellent oxidation, wear resistance, creep resistance and corrosion properties [26]. Thus, they find a huge application in the reinforcement material till date. The most commonly available and used MMCs are silicon carbide particulate $\left(\mathrm{SiC}_{\mathrm{p}}\right)$ reinforced aluminium composite [28]. Aluminium, being light weight is used as structural material in the aerospace, aircraft and automobile industries. With significant improvement thrusted to the weight ratio, the alumina-based composite is best fit in such applications owing to its temperature resistance up to $750^{\circ} \mathrm{F}$ $\left(400^{\circ} \mathrm{C}\right)$. The difficulty faced from the low strength and low melting point of aluminium was solved by using it as a composite with addition of some reinforcement to increase its strength. Silicon carbide ( $\mathrm{SiC}$ ) in the form of particles or whiskers (short fibres) is used with aluminium matrix to replace the existent super alloys. Continuous fibres of $\mathrm{SiC}$ are used in the aerospace applications to reach the desired objective of the high specific strength for design, as compared to that of monolithic materials. The major areas of use of $\mathrm{SiC}$ in aluminium are missiles, aircraft and engines of the automotive sectors. Being cost effective, aluminium has taken its place in such industries [29, 30]. The applications of Al-SiC composites are many, starting from moving parts of vehicle such as bearings, pistons, rotors, etc. to the structural parts of aircraft industries. For example, in order to reduce the heat, noise and vibration, brake rotors are made up of $20 \mathrm{vol} \%$ mixed with aluminium matrix with small amount of magnesium in it, as compared to that of rotors made of cast iron. 


\section{Fabrication techniques of MMCs}

The primary processing in the fabrication of MMCs is done by the following three techniques:
i) Liquid phase fabrication
ii) Solid phase fabrication
iii) Vapour state processing

\section{Liquid Phase Fabrication}

Liquid state fabrication technique, being cost effective is used for acquiring complex shapes with liquid metals in casting industries. Some methods included by the researchers are dispersion [31], stir casting [32], infiltration [33, 34], squeeze casting [35], spraying [36], in-situ fabrication [37] and compo casting [38]. On the other hand, the process cannot control the process parameters and there is a certain chemical reaction between the interface of a liquid metal and reinforcement, which is not desirable.

\section{Solid Phase Fabrication}

The solid phase fabrication technique is used to obtain the best mechanical properties of the MMCs. The fine-grained micro structured composite is obtained with the discontinuous distribution of the reinforcement. The methods used are diffusion bonding [39] and powder metallurgy [40, 41].

\section{Vapour State Processing}

When the vapour phase of the matrix is deposited into the individual reinforcement elements of the component, by means of plasma spraying [42] or physical vapour deposition [43] or chemical deposition [43, 44], then it is said to be the vapour state processing of the composites.

\section{AN OVERVIEW OF ELECTRICAL DISCHARGE MACHINING}

EDM being a sophisticated non-conventional machining process has created its own image for machining those materials that are very difficult to cut in a conventional manner. Out of all non-conventional machining processes, one of the most extensively used processes is the electrical discharge machine (EDM). It finds application in modern industries such as aerospace, aircraft, nuclear, bio-medical sectors etc. Materials of any hardness can be cut by this process [45-48]. The most popular advanced materials that are being machined these days are the MMCs. These materials have gained popularity in the aerospace, underwater and transportation industries [3, 49]. Thus, the machining of MMCs in the non-traditional methods is gaining popularity for their use in extremities. EDM is better known as the thermal erosion process, where the tool and the work-piece are applied with a potential difference in a dielectric medium which establishes an electric field. On the establishment of electric field, free electrons are subjected to the electrostatic forces and move towards the work-piece while gaining velocity. As they gain velocity and energy, there would be collisions between the electrons and dielectric molecules. Spark is generated by this process and subsequently, these high speed electrons impinge upon the work-piece and the heat generation takes place. Subsequently the work material melts and vaporizes.

Figure 1 shows the schematic of EDM where the work-piece is submerged in the dielectric medium with the help of a fixture and the tool is held by the tool holder, being operated by a servo controlled mechanism [4]. The voltmeter, ammeter, and pressure 
gauge show the readings of potential difference, current flow, and pressure, respectively. The filter is used for removing external unwanted particles, if any, from the dielectric so that machining is carried out smoothly.

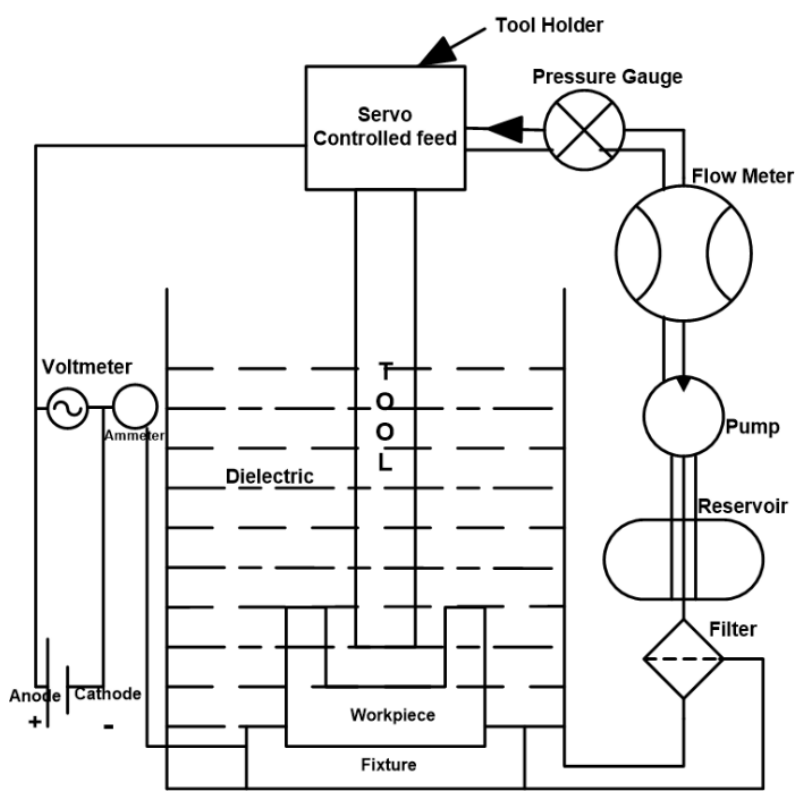

Figure 1. Schematic diagram of EDM [4].

A huge number of MMC components are being manufactured by using EDM which in current trend is used in various applications making EDM gaining pace in the race. A few of them are mentioned in Table 1. EDM has been extensively used in the automotive, aerospace, defence and many such micro industries [2]. Due to this fact of using this unconventional machining process in many advanced industries and being an outstanding developer of low cost products with better quality, EDM has many varieties of its own. The classification goes on with the die-sinking EDM, wire cut EDM (WEDM), dry EDM and rotary disk electrode EDM. The review is based on the die-sinking EDM upon MMCs. Some of the EDM applications upon MMCs are mentioned here in this review.

\section{Wire-Cut EDM}

The Wire-Cut electrical discharge machining (WEDM) was first introduced in the late 1960s to be used in manufacturing industries. It is a production process in which the electro-thermal material erosion takes place from the work-piece by a continuous succession of discrete sparks. The sparks occur between the work-piece and wire which are separated by a continuous stream of the dielectric fed to the machining zone [50]. Heat is generated from the electrical sparks, and a thin strand of metallic wire is used for cutting through the work piece material in the dielectric medium. In Figure 2, the WEDM setup is shown, where the wire is seen driven by pulleys onto the work piece. The process is typically used with the de-ionised water as dielectric and brass, zirconium, copper, etc. as wire electrode.

The Wire-cut EDM is meant to cut thick and harder plates to suit well for punches, dies, tools, etc. There is a low cutting force involved in the WEDM since the low residual stress is involved. It has been employed on various hard to cut materials despite precision accuracies. Moreover, composites have created a place in the field of hard to cut materials, in which, WEDM plays an important role. Various researchers have studied the effect of 
process parameters upon composites with the help of WEDM [51-62]. A semi-empirical model for MRR was proposed to study the thermo-physical properties of the work-piece [63]. The response surface methodology (RSM) approach was used to study the pulseon-time and average gap voltage. Furthermore, Patil and Brahmankar [51] studied the effective results of the combination of reinforcement, feed, current, speed, pulse-on-time, pulse-off-time, servo voltage, surface finish and kerf width on Alumina particulate reinforced aluminium metal matrix composites by WEDM using the Taguchi analysis.

Table 1. Research progress with the use of MMCs using various EDM.

\begin{tabular}{|c|c|c|c|}
\hline Type of MMC used & $\begin{array}{c}\text { Type of } \\
\text { EDM used }\end{array}$ & Remarks & Author (year) \\
\hline $\begin{array}{c}\mathrm{ZrO} 2-\mathrm{TiB} 2, \mathrm{ZrO} 2-\mathrm{TiN}, \mathrm{ZrO} 2, \\
\text { TiC, } \mathrm{ZrO} 2 \mathrm{TiCN}\end{array}$ & $\begin{array}{l}\text { Die Sink } \\
\text { EDM }\end{array}$ & & Put, Vleugels [64] \\
\hline AlSiC & PMEDM & MRR improvement & Syed, Anuraag [65] \\
\hline $\mathrm{Al} / \mathrm{Al} 2 \mathrm{O} 3$ & $\begin{array}{l}\text { PMEDM } \\
\text { (Al) }\end{array}$ & $\begin{array}{c}\text { Increase in MRR and } \\
\text { decrease in SR }\end{array}$ & Talla, Sahoo [66] \\
\hline $\mathrm{A} 16061 / \mathrm{A} 12 \mathrm{O} 3 \mathrm{p} 20 \%$ & $\begin{array}{l}\text { PMEDM } \\
\qquad(\mathrm{SiC})\end{array}$ & $\begin{array}{l}\text { L18 orthogonal array } \\
\text { was used }\end{array}$ & Singh, Maheshwari [67] \\
\hline $\mathrm{Al} / 10 \% \mathrm{SiCp}$ & PMEDM & $\begin{array}{l}\text { MRR increased with } \\
\text { peak current rise }\end{array}$ & Kansal, Singh [68] \\
\hline $\mathrm{Al} / \mathrm{SiCp}$ & WEDM & $\begin{array}{l}\text { Wire breakage showed } \\
\text { limitations }\end{array}$ & $\begin{array}{l}\text { Patil and Brahmankar } \\
\text { [57] }\end{array}$ \\
\hline $\mathrm{Al}-4 \mathrm{Cu}-6 \mathrm{Si} 10 \% \mathrm{SiC}$ & $\begin{array}{l}\text { Die Sink } \\
\text { EDM }\end{array}$ & & Singh, Raghukandan [69] \\
\hline $\mathrm{Al} / \mathrm{ZrO} 2$ & WEDM & $\begin{array}{l}\text { RSM approach was } \\
\text { used for optimization }\end{array}$ & Garg, Manna [60] \\
\hline $\mathrm{Al} 6063 / \mathrm{SiC}_{\mathrm{p}}$ & WEDM & & $\begin{array}{c}\text { Satishkumar, Kanthababu } \\
\text { [54] }\end{array}$ \\
\hline $\mathrm{Al} 7075 / \mathrm{SiC} / \mathrm{Al}_{2} \mathrm{O}_{3}$ & WEDM & $\begin{array}{c}\text { Current has more effect } \\
\text { on kerf }\end{array}$ & Lal, Kumar [53] \\
\hline $\mathrm{AlSi} 7 \mathrm{CuMg} / \mathrm{SiC}$ & $\begin{array}{l}\text { Die Sink } \\
\text { EDM }\end{array}$ & MRR improvement & Iosub, Nagit [70] \\
\hline Al-CuTiB2 & $\begin{array}{l}\text { Die Sink } \\
\text { EDM }\end{array}$ & $\begin{array}{l}\text { TOPSIS method of } \\
\text { optimization }\end{array}$ & $\begin{array}{l}\text { Prabhu and Vinayagam } \\
\text { [71] }\end{array}$ \\
\hline $\mathrm{Al}-\mathrm{TiB}_{2}$ & $\begin{array}{l}\text { Die Sink } \\
\text { EDM }\end{array}$ & $\begin{array}{c}\text { low frequency vibrating } \\
\text { tool }\end{array}$ & $\begin{array}{c}\text { Madhavan and } \\
\text { Balasivanandha Prabu } \\
{[72]}\end{array}$ \\
\hline $\begin{array}{c}\mathrm{AlSi}{ }_{7} \mathrm{Mg} / \mathrm{SiC} \text { and } \\
\mathrm{AlSi}_{7} \mathrm{Mg} / \mathrm{Al}_{2} \mathrm{O}_{3}\end{array}$ & WEDM & & Rozenek, Kozak [55] \\
\hline $\mathrm{Al} 6063 / \mathrm{ZrSiO} 4$ & WEDM & $\begin{array}{l}\text { Impact of process } \\
\text { parameters }\end{array}$ & Sharma, Garg [62] \\
\hline
\end{tabular}




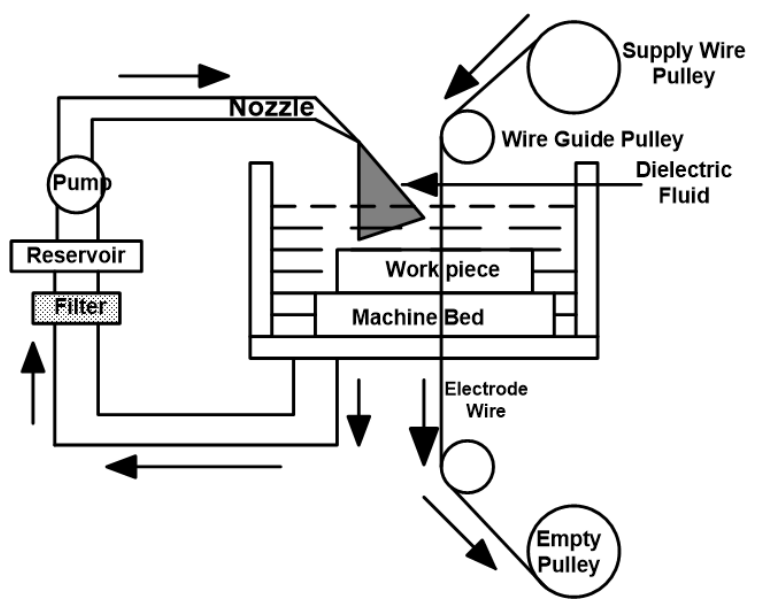

Figure 2. Schematic diagram of WEDM.

Aluminium matrix composite $\left(\mathrm{Al}_{2} \mathrm{O}_{3} / 6061 \mathrm{Al}\right)$ was machined with the analysis of pulse-on-time, surface roughness, cutting speed and width of slit [52]. They found that the wire broke since the cutting speed, width of slit and surface roughness depend on the volume fraction of the $\mathrm{Al}_{2} \mathrm{O}_{3}$ particles. The low concentrated particles indicate better surface roughness and width of slit. Lal, Kumar [53] investigated the effect of parameters upon $\mathrm{Al} 7075 / \mathrm{SiC} / \mathrm{Al}_{2} \mathrm{O}_{3}$ hybrid composite and found out that current has more effects upon kerf than the discharge time. Satishkumar, Kanthababu [54] studied the machining characteristics of $\mathrm{Al} 6063 / \mathrm{SiC}_{\mathrm{p}}$ and developed regression equations to predict the output parameters. Rozenek, Kozak [55] carried out experiments to analyse the machining process parameters upon surface roughness of $\mathrm{AlSi}{ }_{7} \mathrm{Mg} / \mathrm{SiC}$ and $\mathrm{AlSi}{ }_{7} \mathrm{Mg} / \mathrm{Al}_{2} \mathrm{O}_{3}$ using WEDM. They found that the cutting speed of the specified composites was obtained to be 3 and 6.5 times lower than that of the aluminium alloy. Again, Ebeid, Fahmy [56] initiated a mathematical formulation on $\mathrm{AlSiC}_{\mathrm{p}}$ composites and optimized the process parameters (machining voltage, volume fraction, pulse frequency, kerf size and workpiece height of SiC particles) with the WEDM characteristics (MRR, cutting speed and SR).

Patil and Brahmankar [57] conducted experiments on the performance of AlSiCp composites using WEDM by the Taguchi method and found that the cutting speed of an unreinforced alloy was higher than that of the composites, whereas the surface finish in composites was found to be superior to that of the unreinforced alloy. The wire breakage showed limitations post machining process. Shandilya, Jain [58] optimized the process parameters in machining of SiCp/6061 Aluminium MMC by WEDM using RSM. The input parameters pulse-off time, pulse-on time, servo voltage and feed were studied in terms of cutting width. ANNOVA results showed that the voltage and feed rate were more significant than that of the pulse-off time.

Rajaneesh and Sadashivappa [59] studied the behaviour of ZA43/SiCp composite with variations in process parameters; it was revealed that the MRR was reduced and surface roughness increased with the increase in the reinforcement percentage. Garg, Manna [60] conducted experiments to study the effect of WEDM parameters on $\mathrm{Al} / \mathrm{ZrO}_{2}$ particulate reinforced MMC. RSM approach with the central composite design with full factorial was used to optimize and validate the pulse width and duration, voltage and wire tension and feed rate. Srivastava, Dixit [61] showed that the surface roughness increased with the increasing pulse-on time, peak current and volume percentage of reinforcement while machining $\mathrm{Al}_{2} 024 / \mathrm{SiC}$ using WEDM. On the other hand, the MRR increased with 
pulse-on time. With the increase in the reinforcement percentage, MRR decreased. Sharma, Garg [62] investigated the impact of process parameters such as voltage, pulseon time, pulse-off time and current upon cutting rate using WEDM of Al6063/ZrSiO4 composite with the help of a series of experiments. Box-Behnken on RSM was implemented as an experimental approach. The ANNOVA and F-test were performed to reach optimality and it was found that the increase in the current and pulse time shows an increase in the cutting rate. The surface topography of the machined surface showed crater and cracks formation with high pulse-on time and low pulse-off time.

\section{Die Sinking EDM}

The die sinking electrical discharge machining is the most widely used techniques for replication of products such as die-casting, injection moulding, etc [73-75]. It is also better known as the cavity type EDM or volume EDM. The set up consists of an electrode and a work-piece submerged in a dielectric fluid, where the power is supplied to both of these as shown in Figure 3. There is a potential difference developed between the workpiece and electrode. The dielectric breakdown takes place, as the electrode substantially move towards the workpiece during the course of power supply. Spark generation takes place with the formation of plasma from the dielectric break down. The sparks strike upon the electrode, and hence the material is removed from the base metal. With the increasingly removal of the base metal, the spark gap increases, hence lowering the electrode for uninterrupted machining. Kathiresan and Sornakumar [76] carried out series of experiments using EDM upon LM24 Al-SiC MMCs and studied the resultant effect of volume fraction of composites and effect of current on MRR and surface roughness. It was found that the MRR and surface roughness increased with the increasing current. Garg, Singh [77] reviewed a comparative study of the die-sinking $\mathrm{EDM}$ and WEDM on the metal matrix composites. It was concluded that the $\mathrm{SiC}$ reinforced composites are popular among researchers till then, and work includes the performance characteristic analysis and optimization. The study of EDM characteristics of $\mathrm{AlSi} 7 \mathrm{CuMg} / \mathrm{SiC}$ metal matrix composites [70] showed that an increase in electrode diameter increases the MRR and decreases the tool wear rate. It was also concluded that the increase in the pulse-on time increases the tool wear rate and MRR. Nanimina, AbdulRani [78] investigated the effect of process parameters upon Aluminium MMCs. They considered the pulse-on-time, pulse-off-time and peak current and found that an increase in the pulse-on-time and current increases the MRR. The vice-versa showed more tool wear. Ahamed, Asokan [27] conducted a study on the inclusions of $\mathrm{B}_{4} \mathrm{C}$ and glass reinforced $\mathrm{AlSiC}$ composites. They found that an increase in the reinforcement ratio decreases the surface defects or cracks and the MRR. The in-situ composite fabrication method has limited work and Prabu, Ramadoss [79] experimented upon Al-TiB 2 with the help of a low frequency vibrating tool. The results showed that with the increasing current, the MRR and surface defects increase. Prabhu and Vinayagam [71] carried out the parametric optimization using TOPSIS, upon in-situ composite $\mathrm{Al}-\mathrm{CuTiB}$, considering MRR, tool wear rate, and surface roughness. The results were found in good agreement with the run while optimization.

\section{Powder mixed EDM}

Powder mixed electrical discharge machining (PMEDM) is the recent generation development to match the innovative technologies. Technologies, no doubt, are reaching beyond limits but beside all innovations, super-finished products have their own image in industries. Thus, the super-finished products can only be obtained by enhancing the 
quality, capability, and smartness of the machines these days. Catalysts play an important role in improving the surface quality of products in machining. In EDM, powders play an important role, which when mixed with the dielectric medium, giving the super quality product. Hence, powders are useful in EDM to improve the performance characteristic properties as well as all capabilities of the machine tool. The process involves introduction of fine powders into the dielectric medium to be thoroughly mixed into the fluid. The importance of using the powders is to enhance the breakdown attributes of the dielectric. As the insulating strength of the dielectric fluid decrease, the spark gap between the tool and work-piece increases hence making flushing of debris uniform. Uniformity in flushing results in the improvement of MRR and surface quality.

The working principle of the powder mixed EDM is similar to that of EDM but with few changes in the system. Figure 3 depicts the working principle of PMEDM. With the application of voltage, the powders show energetic behaviour and follow zigzag movement within the dielectric fluid. The powder particles get charged up and are accelerated due to the effect of electric field. The gap between the work-piece and the tool is filled with powder and dielectric mixture, which promotes the breakdown of the dielectric. The spark generation area allows the particles to arrange themselves in chain structure and direction of the current flow permitting the interlocking of the powder particles. A bridging effect is produced out of this chaining of particles, due to the insulating strength of the dielectric decreases. The short circuit occurs during the process that helps in faster sparking and hence faster erosion from the surface of the work-piece material. This leads to the increase in MRR.

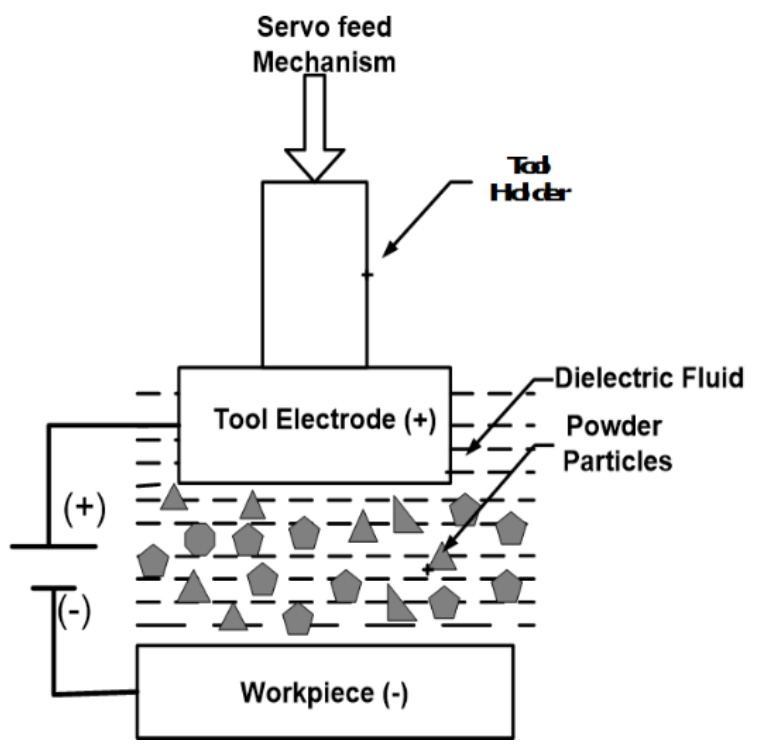

Figure 3. Working principle of PMEDM.

The powders for the powder mixed electrical discharge machining has been used since the 1980s when Erden and Bilgin [80] first reported that the addition of powder particles $(\mathrm{Al}, \mathrm{Cu}, \mathrm{Fe})$ in the dielectric improved its breakdown characteristics. Many researchers since then started to experiment the use of powder particles in the dielectric. The list goes on with the use of graphite powders by Jeswani [81] . Silicon, aluminium and graphite powders were used by Narumiya, Mohri [82] and they showed that the increase in gap correlates with the concentration of the powders. YAN and CHEN [83] proved that powder particles reduced the surface cracks with the use of alumina particle. 
The addition of silicon carbide and aluminium powders into the kerosene dielectric in micro-slit machining of Ti-alloy resulted to the high MRR and material removal depth and increasing gap distance [7]. Tzeng and Lee [84] studied the effect of powder on machine efficiency and concluded that 70-80nm sized powder showed the highest MRR and lowest increment of spark gap.

Table 2. Powders used by researchers.

Experimentation done with the help of urea in distilled water resulted in the formation of TiN layer, better wear resistance on machined surface and increased MRR and electrode wear rate (EWR) with the increasing peak current [91]. Some powders used

\begin{tabular}{|c|c|c|c|}
\hline Powder used & Author (Year) & $\begin{array}{l}\text { Dielectric } \\
\text { fluid }\end{array}$ & Comments (If any) \\
\hline $\begin{array}{l}\text { Aluminium, } \\
\mathrm{SiC}\end{array}$ & $\begin{array}{l}\text { Tzeng and Lee } \\
{[84]}\end{array}$ & Kerosene & $\begin{array}{l}\text { With the increase in particle size, MRR } \\
\text { and discharge gap increased. Al } \\
\text { produced larger gap than that of } \mathrm{SiC}\end{array}$ \\
\hline $\mathrm{SiC}$ & Chow, Yang [85] & Pure water & Process applied to produce micro-slit \\
\hline Titanium & $\begin{array}{l}\text { Furutani, Sato } \\
{[86]}\end{array}$ & Kerosene & Accretion process application \\
\hline $\mathrm{Al}$ & $\begin{array}{l}\text { Syed and } \\
\text { Palaniyandi [87] }\end{array}$ & $\begin{array}{l}\text { Distilled } \\
\text { water }\end{array}$ & Improvement of MRR, TWR and SR \\
\hline $\begin{array}{l}\text { Copper, } \\
\text { diatomite, } \mathrm{Al}\end{array}$ & $\begin{array}{l}\text { Muniu, Nyaanga } \\
\text { [88] }\end{array}$ & $\begin{array}{l}\text { Distilled } \\
\text { water }\end{array}$ & $\begin{array}{l}\text { MRR increases to maximum and then } \\
\text { decreases with further powder } \\
\text { concentration }\end{array}$ \\
\hline Chromium & $\begin{array}{l}\text { Garg and Ojha } \\
\text { [89] }\end{array}$ & & \\
\hline Tungsten & Khedkar N K [90] & EDM oil & Higher coefficient of friction in PMEDM \\
\hline Urea & Yan, Tsai [91] & $\begin{array}{l}\text { Distilled } \\
\text { water }\end{array}$ & $\begin{array}{l}\text { Improved friction and wear } \\
\text { characteristics }\end{array}$ \\
\hline $\mathrm{CNT}$ & $\begin{array}{l}\text { Mai, Hocheng } \\
{[92]}\end{array}$ & & Machining efficiency increased by $66 \%$ \\
\hline $\begin{array}{l}\text { Si,tungsten, } \\
\text { graphite }\end{array}$ & $\begin{array}{l}\text { Bhattacharya, } \\
\text { Batish [93] }\end{array}$ & $\begin{array}{l}\text { Kerosene, } \\
\text { EDM oil }\end{array}$ & \\
\hline $\mathrm{MoS}_{2}$ & $\begin{array}{l}\text { Prihandana, } \\
\text { Mahardika [94] }\end{array}$ & & Ultrasonic vibration was used \\
\hline Nickel & $\begin{array}{l}\text { Garg and Ojha } \\
\text { [89] }\end{array}$ & Kerosene & Optimization was done using software \\
\hline Nano-graphite & $\begin{array}{l}\text { Choudhary and } \\
\text { Jadoun [49] }\end{array}$ & & Machining time reduced five times faster \\
\hline $\mathrm{SiC}$ & Rival [96] & Kerosene & Higher MRR and SR values \\
\hline
\end{tabular}

by researchers are mentioned in Table 2. With the development of super alloys, composites and advanced materials the machining became a challenge for researchers. Out of many researchers, few started working on the metal matrix composites with powder mixed EDM. Kansal, Singh [68] developed an optimum machining conditions for PMEDM with Al powders upon Al-10\% SiC MMC using the response surface 
approach. The results show that MRR increased with the increase in peak current for no specific value of pulse duration. Moreover, the surface roughness increased with the peak current and pulse duration rise. Peças and Henriques [97] studied the effect of Silicon powder in dielectric with a conclusion that a small amount of additive in dielectric significantly reduces the crater wear and white layer thickness. They also concluded that powder concentration affects the surface characteristics. Singh, Maheshwari [67] in their


quantitative analytical method to optimize the process parameters. The Length's method was used to analyse the results and it was found that as compared to the conventional EDM, PMEDM gave better MRR and reduced surface roughness. Talla, Sahoo [66] fabricated and machined $\mathrm{Al} / \mathrm{Al}_{2} \mathrm{O}_{3} \mathrm{MMC}$ with PMEDM using aluminium powder. They developed semi-empirical models as well as carried out multi-response optimization using the grey relational analysis. The proposed parameters include powder concentration $=4 \mathrm{~g} / \mathrm{L}$, pulse-on-time $=150 \mathrm{~ms}$, peak current $=3 \mathrm{~A}$ and $85 \%$ duty cycle. Singh and Yeh [98] did multi-objective optimization using the grey relational analysis for $6061 \mathrm{Al} / \mathrm{Al}_{2} \mathrm{O}_{3} \mathrm{MMC}$ with $\mathrm{SiC}$ abrasives using PMEDM and found the results for low surface roughness and high MRR.

Micro particles came into existence with the trending technologies.Prihandana, Mahardika [94] suspended $\mathrm{MoS}_{2}$ in a micro form into the dielectric fluid and an extra ultrasonic vibration. The results show that ultrasonic vibration and the addition of micro particles significantly increase the MRR with improvement in the surface quality. In another set of experiments, [94]introduced graphite powders in the dielectric fluid and reduced the machining time by five times faster than that required in the pure dielectric. Moreover, the vibration of the electrode upon the work-piece shows significant variations in machining time up to three times faster. Garg and Ojha [89] introduced the nickel micro powder in the dielectric fluid to analyse the performance upon EN 19 steel. In a further study, Ojha, Garg [99] varied the electrode shapes upon the same material using the nickel micro powders and developed an optimization model to assist the process parameters. During the course of super-finished products from the powder mixed electrical discharge machining with the help of introduction of powders to micro-powders, the race still abides the technological advancements. The greediness of achieving yet more of something available i.e. super-finishing to ultra-finishing has made researchers to work harder. The growing pace of nano-technology has astonished many researchers to think of introducing nanoparticles for many machining applications. The list of using nanoparticles in EDM are although few, overall analysis showed that in the era of manufacturing nanoparticles as powder mixed in EDM gives the best surface finish to date. To this aspect, Jahan, Rahman [100] studied the effect of nano-particles and micro-particles in EDM of WC-Co and reported that the smoother and defect-free surface was obtained as compared to that of the die-sinking micro-EDM. The lowest and highest surface roughness value was found to be $37 \mathrm{~nm}$ and $17 \mu \mathrm{m}$ respectively. Choudhary and Jadoun [49] proposed a novel method of using discharge pulse to improve the accuracy of nano-graphite powder mixed dielectric for the micro-EDM process. The Nano-graphite with ultrasonic vibration of the dielectric fluid improved surface quality and reduced machining time. Prihandana, Sriani [101] worked on improving the machining time in micro EDM in addition to workpiece vibration and nano-graphite powder mixed in dielectric fluid. They found that machining time was three times faster than the conventional one. Tseng, Lee [102] in their work focused in the preparation of the silver nanofluid by the EDM system. They derived the relationship between the process parameters and product characteristics. The system used intense energy to splatter the electrode surface in dielectric fluid, and this method has a 
wide application in the nanofabrication technology, for example, $\mathrm{Ni}-\mathrm{C}$ powders in pure ethanol, silver nano fluid in ethylene glycol, gold nanoparticles in water or ethanol and carbon nanotubes (CNTs). Tseng, Lee [102] explained that for the nanofluid application issue, nanofluid must be strongly stable which does not sediment before any application or analysis but many other factors affect the stability of suspension such as concentration of particles, particle size in diameter, solution properties, electrical conductivity and $\mathrm{pH}$. A. Singh [103] studied the surface characteristics with the use of mixed carbon nano tubes (CNTs) in EDM to obtain high surface finish value because of the high thermal conductivity of CNTs.

\section{INFLUENCE OF PROCESS PARAMETERS}

The electrical discharge machining has various process parameters that affect the performance parameters surface roughness and recasts layer thickness and material removal rate $[73,104-106]$. The quality of component is solely affected by the process parameters. Considering the powder mixed EDM, the process parameters can be classified as electrical, non-electrical, dielectric, electrode and powder parameters. The electrical process parameters include the peak current, input voltage, pulse-on-time, and pulse-off-time. On the other hand, the non-electrical process parameters include nozzle flushing time, electrode lifting time and working time. The dielectric parameters include the types of the dielectric used and dielectric strength whereas the electrode parameters are the types of the electrode, material, and size. The powder parameters are its type, concentration, size, shape, conductivity, etc.

\section{OPTIMIZATION TECHNIQUES USED IN EDM}

The recent developments in the changes to EDM with its sophisticated use in manufacturing industries have led to the rise of effective and economic technique requirements [5]. The needs of finished products have attracted many industries towards the art of EDM. The arising of super-finished and ultra-finished products requires a high cost in the technique and hence, optimality in terms of price and efficiency has to be crosschecked during the course of machining [4]. Many researchers have led their hands in reaching out an optimality to get better access to[107, 108] the machine tool. To this aspect, optimization techniques such as the Taguchi analysis [109], Grey relational model [110], Response Surface Methodology [111-115], Particle Swarm optimization [116], etc. were used by researchers. Some of which have been highlighted in this review work. Kolli and Kumar [109] employed the Taguchi method to optimize the surfactant and graphite powder concentration in dielectric fluid for the machining of Ti-6Al-4V using EDM. The results showed that the addition of graphite powder and surfactant in the dielectric fluid improves the MRR, reduces the SR and TWR and recasts layer thickness (RLT). Ho and Newman [2] adopted the non-dominated sorted genetic algorithm (NSGA-II) to optimize the responses of powder mixed EDM and found that the use of powder mixed dielectric promotes the reduction of surface roughness and enhances MRR. Padhee, Nayak [4] carried out a comparative study of the electrode performances by the desirability approach and ANNOVA using Fuzzy model in EDM and found that current was the most influencing factor followed by the pulse-on-time and pulse-off-time. Sengottuvel, Satishkumar [111] presented a model and analysed the rapidly resolidified layer of spheroidal graphite (SG) cast iron in the EDM process using the RSM approach. The results of ANNOVA indicated that the quantity and area fraction of the graphite particle 
are the most influential factors on the rapidly resolidified layer thickness and ridge density in EDM process. The layer thickness decreases with the increase in the diameter of graphite particle. Chiang, Chang [117] investigated the influence of various EDM process parameters like pulse current, pulse-on time, tool work time and tool lift time on various aspects of surface integrity like the white layer thickness (WLT), surface crack density (SCD) and surface roughness (SR). Using the response surface methodology (RSM), it was found that the surface crack density was the most sensitive response and hence to be chosen and analysed carefully. In another study, Dewangan, Gangopadhyay [110] optimized the parameters of EDM using the grey-fuzzy logic based hybrid optimization technique. The results indicate that the pulse-on time was the most significant parameter followed by discharge current.

Dewangan, Gangopadhyay [116] studied the performance of tool materials (graphite, niobium, titanium, tantalum, tungsten) upon ZrB2-SiC MMC and optimized the performance parameters using the Particle swarm optimization (PSO) algorithm technique. Sivasankar S [118] investigated the influence of process parameters (current, voltage, pulse-on-time, pulse-off-time) while machining Al6061/10\%SiC MMC and found the results to be in good agreement with other researchers. Singh, Kumar [119] used the artificial neural network (ANN) technique to develop a reliable model in predicting the tool wear rate with the least predictive error. They used graphite powder in the dielectric to reduce the tool wear rate during machining MMCs. The peak current was found to be the most significant factor and then the powder concentration. Agrawal, Dubey [120] an optimization outline for the EDM process parameters of the WC/Co composites with the help of NSGA-II. With the technological advancements, soft computing techniques and multi-response optimization techniques are being adopted to obtain the best compatible parameters of EDM. To this aspect, Kanagarajan, Karthikeyan [121] used the grey relational approach (GRA) and Taguchi, a combination of multioptimization to study the tool wear exit and entry clearance, machining duration and number of short-circuits generated. Jung and Kwon [122] also used the same GRA technique on $\mathrm{EDM}$ of $\mathrm{Al} 10 \% \mathrm{SiC}_{\mathrm{p}}$ composite for multi-optimization for multiple responses. The experimental data proves that there is visible improvement in the EDM characteristics. A mathematical model was developed with the help of the regression analysis by Singh, Raghukandan [69] for MRR and TWR, while the electro-discharge machining of $\mathrm{Al}-4 \mathrm{Cu}-6 \mathrm{Si}$ alloy was reinforced with $10 \% \mathrm{SiC}$ composites.

\section{CONCLUSIONS}

The study presents the wide use of EDM on metal matrix composites. The powder mixed EDM gives better surface finish as compared to that of WEDM and Die sinking EDM as depicted from the previous work. The powders introduced in the EDM help in increasing the spark gap between the electrode and the workpiece and reducing the insulating strength of the dielectric medium. This improves the MRR, makes the process stable and reduces the surface roughness. The electrical density was reduced on the machining spot with the addition of powders. The use of the metal matrix composites in EDM implies its vast application in the modern industries as stated in the work. In order to obtain the super-finished surfaces on such materials, EDM has been used. The super finished composites are thus used in the precision industries. The review depicts various powders used in EDM and the results show better surface finish and improvement of MRR. Many powders in the micro to nano form have been used yet it is evident that the use of nano powders was not much prevalent among the researchers. More and more work can be 
carried out with the use of nano powders. The optimization techniques used by various researchers with different techniques were mentioned in the review. It is seen that the use of soft computing techniques such as the artificial neural network, genetic algorithm, particle swarm optimization, etc. have not been used by many researchers in the case of powder mixed EDM. Moreover, the process parameters in the nano powder mixed dielectric in EDM are optimized using traditional methods of optimization. The use of soft computing techniques has been less prevalent. Thus, further work can be done using various other powders in EDM on different MMCs.

\section{ACKNOWLEDGEMENTS}

The authors would like to be obliged to KIIT. University, Bhubaneswar, Odisha, India for providing necessary documents and downloadable research articles for completion of the review article.

\section{REFERENCES}

[1] Kozak J, Rajurkar KP. Hybrid machining process evaluation and development. Proceedings of 2 nd international conference on machining and measurements of sculptured surfaces, Keynote Paper, Krakow, 2000. p. 501-36.

[2] Ho K, Newman S. State of the art electrical discharge machining (EDM). International Journal of Machine Tools and Manufacture. 2003;43:1287-300.

[3] Popescu IN, Zamfir S, Anghelina VF, Rusanescu CO. Processing by P/M route and characterization of new ecological aluminum matrix composites (AMC). International Journal of Mechanics. 2010;4:43-52.

[4] Padhee S, Nayak N, Panda S, Dhal P, Mahapatra S. Multi-objective parametric optimization of powder mixed electro-discharge machining using response surface methodology and non-dominated sorting genetic algorithm. Sadhana. 2012;37:223-40.

[5] Wong Y, Lim L, Rahuman I, Tee W. Near-mirror-finish phenomenon in EDM using powder-mixed dielectric. Journal of Materials Processing Technology. 1998;79:30-40.

[6] Ming QY, He LY. Powder-suspension dielectric fluid for EDM. Journal of materials processing technology. 1995;52:44-54.

[7] Chow H-M, Yan B-H, Huang F-Y, Hung J-C. Study of added powder in kerosene for the micro-slit machining of titanium alloy using electro-discharge machining. Journal of Materials Processing Technology. 2000;101:95-103.

[8] Schumacher B. About the role of debris in the gap during electrical discharge machining. CIRP Annals-Manufacturing Technology. 1990;39:197-9.

[9] Abu Bakar MH, Raja Abdullah RI, Md. Ali MA, Kasim MS, Sulaiman MA, Ahmad SSN, et al. Surface integrity of LM6 aluminum metal matrix composite when machined with high speed steel and uncoated carbide cutting tools. Journal of Mechanical Engineering and Sciences. 2014;6:854-62.

[10] Maleque MA, Rahman MM, Hossain S. Conceptual design of aluminium metal matrix composite brake rotor system. International Conference on Advances in Materials and Processing Technologies, AMPT 20092011. p. 1648-53.

[11] Adebisi AA, Maleque MA, Rahman MM. Metal matrix composite brake rotors: Historical development and product life cycle analysis. International Journal of Automotive and Mechanical Engineering. 2011;4:471-80. 
[12] Maleque MA, Radhi M, Rahman MM. Wear study of Mg-SiCp reinforcement aluminium metal matrix composite. Journal of Mechanical Engineering and Sciences. 2016;10:1758-64.

[13] Rihayat T, Salim S, Agusnar H, Fajri, Zaimahwati. Synthesis of polyurethane/clay nanocomposites based palm oil polyol coating. Journal of Mechanical Engineering and Sciences. 2015;9:1580-6.

[14] Fatchurrohman N, Sulaiman S, Sapuan SM, Ariffin MKA, Baharuddin BTHT. Analysis of a Metal Matrix Composites Automotive Component. International Journal of Automotive and Mechanical Engineering. 2015;11:2531-40.

[15] Prihandana GS, Mahardika M, Hamdi M, Wong Y, Mitsui K. Accuracy improvement in nanographite powder-suspended dielectric fluid for microelectrical discharge machining processes. The International Journal of Advanced Manufacturing Technology. 2011;56:143-9.

[16] Yih-Fong $\mathrm{T}, \mathrm{Fu}-\mathrm{Chen} \mathrm{C}$. Investigation into some surface characteristics of electrical discharge machined SKD-11 using powder-suspension dielectric oil. Journal of Materials Processing Technology. 2005;170:385-91.

[17] Tan P-C, Yeo S-H, Tan Y-V. Effects of nanopowder additives in micro-electrical discharge machining. International Journal of Precision Engineering and Manufacturing. 2008;9:22-6.

[18] Prasad K, Mahamani A, Sravani PS, Mounika K. Electrical discharge machining of the composites-A.

[19] Asif Iqbal AKM, Arai Y. Study on Low-Cycle Fatigue Behavior of Cast Hybrid Metal Matrix Composites. International Journal of Automotive and Mechanical Engineering. 2015;11:2504-14.

[20] Aeyzarq Muhammad Hadzreel MR, Siti Rabiatull Aisha I. Effect of reinforcement alignment on the properties of polymer matrix composite. Journal of Mechanical Engineering and Sciences. 2013;4:548-54.

[21] Suresh S. Fundamentals of metal-matrix composites: Elsevier; 2013.

[22] Mehrabian R, Riek R, Flemings M. Preparation and casting of metal-particulate non-metal composites. Metallurgical Transactions. 1974;5:1899-905.

[23] Lloyd D. Particulate reinforced composites produced by molten metal mixing. Proc of TMS Symp: High Performance Composites for the 1990's, S1991. p. 3345.

[24] Taya M, Arsenault RJ. Metal matrix composites: thermomechanical behavior: Elsevier; 1989.

[25] Degischer HP. Innovative light metals: metal matrix composites and foamed aluminium. Materials \& Design. 1997;18:221-6.

[26] Nixon TD, Cawley JD. Oxidation inhibition mechanisms in coated carbon-carbon composites. Journal of the American Ceramic Society. 1992;75:703-8.

[27] Ahamed AR, Asokan P, Aravindan S. EDM of hybrid Al-SiCp-B4Cp and AlSiCp-Glassp MMCs. The International Journal of Advanced Manufacturing Technology. 2009;44:520-8.

[28] Bedir F, Ogel B. Investigation of hardness, microstructure and wear properties of $\mathrm{SiC}-\mathrm{p}$ reinforced $\mathrm{Al}$ composites. Proceeding of the 11th International Conference on Machine Design and Production, Turkey2004.

[29] Karthikeyan R, Narayanan PL, Naagarazan R. Mathematical modelling for electric discharge machining of aluminium-silicon carbide particulate composites. Journal of Materials Processing Technology. 1999;87:59-63. 
[30] Rao CS, Upadhyaya G. 2014 and 6061 aluminium alloy-based powder metallurgy composites containing silicon carbide particles/fibres. Materials \& Design. 1995;16:359-66.

[31] Sutherland TJ GJ. Fatigue crack propagation in dispersion strengthened aluminium alloy metal matrix composite (MMC). Metal Powder Report. 1992;47:57-8.

[32] Gopalakrishnan S, Murugan N. Production and wear characterisation of AA 6061 matrix titanium carbide particulate reinforced composite by enhanced stir casting method. Composites Part B: Engineering. 2012;43:302-8.

[33] Kevorkijan V. Mg AZ80/SiC composite bars fabricated by infiltration of porous ceramic preforms. Metallurgical and Materials Transactions A. 2004;35:707-15.

[34] Bahraini M, Schlenther E, Kriegesmann J, Graule T, Kuebler J. Influence of atmosphere and carbon contamination on activated pressureless infiltration of alumina-steel composites. Composites Part A: Applied Science and Manufacturing. 2010;41:1511-5.

[35] Cayron C, Buffat P, Hausmann C, Beffort O. About the epitaxial growth of Mgsubgrains on $\mathrm{A} 12 \mathrm{MgC} 2$ interfacial carbides in a squeeze cast $\mathrm{Mg}-4 \mathrm{Al} / \mathrm{T} 300$ metal matrix composite. Journal of Materials Science Letters. 1999;18:1671-4.

[36] Sansoucy E, Marcoux P, Ajdelsztajn L, Jodoin B. Properties of SiC-reinforced aluminum alloy coatings produced by the cold gas dynamic spraying process. Surface and Coatings Technology. 2008;202:3988-96.

[37] Man H, Zhang S, Cheng F, Yue T. In situ synthesis of TiC reinforced surface MMC on Al6061 by laser surface alloying. Scripta Materialia. 2002;46:229-34.

[38] Sajjadi S, Parizi MT, Ezatpour H, Sedghi A. Fabrication of A356 composite reinforced with micro and nano $\mathrm{Al} 2 \mathrm{O} 3$ particles by a developed compocasting method and study of its properties. Journal of Alloys and Compounds. 2012;511:226-31.

[39] Muratoglu O K SSH. US Patent No 8,530,057. Washington, DC: U.S. Patent and Trademark Office 2013.

[40] Surreddi K, Scudino S, Bartusch B, Murty B, Liu G, Prashanth K, et al. Mechanical properties of Al-based metal matrix composites reinforced with $\mathrm{Zr}$ based glassy particles produced by powder metallurgy. 2009.

[41] Tatar C, Özdemir N. Investigation of thermal conductivity and microstructure of the $\alpha-\mathrm{Al}_{2} \mathrm{O}_{3}$ particulate reinforced aluminum composites (Al/Al $2 \mathrm{O} 3-\mathrm{MMC}$ ) by powder metallurgy method. Physica B: Condensed Matter. 2010;405:896-9.

[42] Kang H-K, Kang SB. Thermal decomposition of silicon carbide in a plasmasprayed $\mathrm{Cu} / \mathrm{SiC}$ composite deposit. Materials Science and Engineering: A. 2006;428:336-45.

[43] Tither D, Ahmed W, Sarwar M, Ahmed E. Application of diamond-like carbon coatings deposited by plasma-assisted chemical vapour deposition onto metal matrix composites for two-stroke engine components. Journal of Materials Science Letters. 1995;14:1062-4.

[44] Lin T-C, Hon M-H. Synthesis and microstructure of the Ti $3 \mathrm{SiC} 2$ in $\mathrm{SiC}$ matrix grown by chemical vapor deposition. Ceramics International. 2008;34:631-8.

[45] Rahman Khan MA, Rahman MM, Kadirgama K. Neural network modeling and analysis for surface characteristics in electrical discharge machining. In: Al Nur M, Ali MA, Ali M, editors. 10th International Conference on Mechanical Engineering, ICME 2013: Elsevier Ltd; 2014. p. 631-6. 
[46] Khan MAR, Rahman MM, Kadirgama K. Electrode wear rate of graphite electrodes during electrical discharge machining processes on titanium alloy Ti5Al-2.5SN. International Journal of Automotive and Mechanical Engineering. 2014;9:1782-92.

[47] Khan MAR, Rahman MM, Kadirgama K. Electrode Wear Rate of Graphite Electrodes during Electrical Discharge Machining Processes on Titanium Alloy Ti-5Al-2.5Sn. International Journal of Automotive and Mechanical Engineering. 2014;9:1792-.

[48] Ashikur Rahman Khan M, Rahman MM. Surface study in a non-conventional (electrical discharge machining) process for grade 6 titanium material. Jurnal Teknologi (Sciences and Engineering). 2014;68:89-93.

[49] Choudhary SK, Jadoun R. Current advanced research development of electric discharge machining (EDM): a review. International Journal of Research in Advent Technology. 2014;2:273-97.

[50] Jameson E. Electrical discharge machining: tooling, methods, and applications: Society of Manufacturing Engineers; 1983.

[51] Patil NG, Brahmankar P. Some studies into wire electro-discharge machining of alumina particulate-reinforced aluminum matrix composites. The International Journal of Advanced Manufacturing Technology. 2010;48:537-55.

[52] Yan BH, Tsai HC, Huang FY, Lee LC. Examination of wire electrical discharge machining of $\mathrm{Al} 2 \mathrm{O} 3 \mathrm{p} / 6061 \mathrm{Al}$ composites. International Journal of Machine Tools and Manufacture. 2005;45:251-9.

[53] Lal S, Kumar S, Khan ZA, Siddiquee AN. Optimization of wire electrical discharge machining process parameters on material removal rate for Al7075/SiC/A12O3 hybrid composite. Proceedings of the Institution of Mechanical Engineers, Part B: Journal of Engineering Manufacture. 2014:0954405414533511.

[54] Satishkumar D, Kanthababu M, Vajjiravelu V, Anburaj R, Sundarrajan NT, Arul $\mathrm{H}$. Investigation of wire electrical discharge machining characteristics of Al6063/SiCp composites. The International Journal of Advanced Manufacturing Technology. 2011;56:975-86.

[55] Rozenek M, Kozak J, Dabrowski L, Łubkowski K. Electrical discharge machining characteristics of metal matrix composites. Journal of Materials Processing Technology. 2001;109:367-70.

[56] Ebeid S, Fahmy R, Habib S. Mathematical Modelling for Wire Electrical Discharge Machining of Aluminum-Silicon Carbide Composites. Proceedings of the 34th International MATADOR Conference: Springer; 2004. p. 147-52.

[57] Patil N, Brahmankar P. Some investigations into wire electro-discharge machining performance of $\mathrm{Al} / \mathrm{SiCp}$ composites. International Journal of Machining and Machinability of Materials. 2006;1:412-31.

[58] Shandilya P, Jain P, Jain N. RSM and ANN modeling approaches for predicting average cutting speed during WEDM of SiC p/6061 Al MMC. Procedia Engineering. 2013;64:767-74.

[59] Rajaneesh NM, Sadashivappa K. Effect of machining parameters on MRR and surface roughness in machining of ZA43/SiCp composite by WEDM. International Journal of Applied Science and Engineering 11 (3). 2013:317-30.

[60] Garg SK, Manna A, Jain A. Multi-objective optimization of machining characteristics during wire electrical discharge machining of $\mathrm{A} 1 / \mathrm{ZrO} 2$-particulate 
reinforced metal matrix composite. Journal of Engineering Research. 2013;1:14560.

[61] Srivastava A, Dixit AR, Tiwari S. Experimental Investigation of Wire EDM Process Parameteres on Aluminum Metal Matrix Composite Al2024/SiC. International Journal of Advance Research and Innovation. 2014;2:511-5.

[62] Sharma A, Garg MP, Goyal KK. Prediction of Optimal Conditions for WEDM of Al 6063/ZrSiO 4 (p) MMC. Procedia Materials Science. 2014;6:1024-33.

[63] Patil NG, Brahmankar P. Determination of material removal rate in wire electrodischarge machining of metal matrix composites using dimensional analysis. The International Journal of Advanced Manufacturing Technology. 2010;51:599-610.

[64] Put S, Vleugels J, Van der Biest O, Trueman C, Huddleston J. Die sink electrodischarge machining of zirconia based composites. British ceramic transactions. 2013.

[65] Syed KH, Anuraag G, Hemanth G, Subahan SA. Powder-Mixed EDM Machining of Aluminium-Silicon Carbide Composites. Indian Journal of Science and Technology. 2015;8:133-7.

[66] Talla G, Sahoo DK, Gangopadhyay S, Biswas C. Modeling and multi-objective optimization of powder mixed electric discharge machining process of aluminum/alumina metal matrix composite. Engineering Science and Technology, an International Journal. 2015;18:369-73.

[67] Singh S, Maheshwari S, Dey A, Pandey PC. Experimental results and analysis for Electrical Discharge Machining (EDM) of aluminium metal matrix composites with powder-mixed dielectric: Lenth's method. International Journal of Manufacturing Technology and Management. 2010;21:67-82.

[68] Kansal H, Singh S, Kumar P. An experimental study of the machining parameters in powder mixed electric discharge machining of $\mathrm{Al}-10 \% \mathrm{SiCP}$ metal matrix composites. International Journal of Machining and Machinability of Materials. 2006;1:396-411.

[69] Singh PN, Raghukandan K, Pai B. Optimization by grey relational analysis of EDM parameters on machining $\mathrm{Al}-10 \% \mathrm{SiC} \mathrm{P}$ composites. Journal of Materials Processing Technology. 2004;155:1658-61.

[70] Iosub A, Nagit G, Negoescu F. Tool wear investigation in electric discharge machining of aluminum matrix composite materials. Avilable at http://www tcm ugal ro/tmb/2009/140 pdf. 2009.

[71] Prabhu S, Vinayagam B. Multiresponse Optimization of Edm Process with Nanofluids Using Topsis Method and Genetic Algorithm/Zastosowanie metody TOPSIS i algorytmów genetycznych do wielokryterialnej optymalizacji procesu obróbki elektroiskrowej $\mathrm{z}$ uzyciem nanopłynów. Archive of Mechanical Engineering. 2016;63:45-71.

[72] Madhavan S, Balasivanandha Prabu S. Deformation behaviour and failure mechanisms of Al-TiB2 in situ composites. Materials Science and Technology. 2013;29:268-72.

[73] Khan MAR, Rahman MM, Noor MM, Kadirgama K, Maleque MA. Current research trends on dry, near-dry and powder mixed electrical discharge machining. International Conference on Advances in Materials and Processing Technologies, AMPT 20092011. p. 956-61.

[74] Khan MAR, Rahman MM, Kadirgama K, Maleque MA, Ishak M. Prediction of Surface Roughness of Ti-6Al-4V in Electrical Discharge Machining: A 
Regression Model. Journal of Mechanical Engineering and Sciences. 2011;1:1624.

[75] Kumar S, Singh R. Investigation of Surface Properties in Manganese Powder Mixed Electrical Discharge Machining of OHNS And D2 Die Steels. International Journal of Automotive and Mechanical Engineering. 2010;2:181-99.

[76] Kathiresan M, Sornakumar T. EDM Studies on aluminum alloy-silicon carbide composites developed by vortex technique and pressure die casting. Journal of minerals and materials characterization and engineering. 2010;9:79.

[77] Garg R, Singh K, Sachdeva A, Sharma VS, Ojha K, Singh S. Review of research work in sinking EDM and WEDM on metal matrix composite materials. The International Journal of Advanced Manufacturing Technology. 2010;50:611-24.

[78] Nanimina AM, Abdul-Rani A, Ahmad F, Zainuddin A, Lo SJ. Effects of electrodischarge machining on aluminium metal matrix composite. Journal of Applied Sciences. 2011;11:1668-72.

[79] Prabu M, Ramadoss G, Narendersingh P, Christy T, Eswaran VV. Electrical discharge machining of Al-TiB2 with a low-frequency vibrating tool. Science and Engineering of Composite Materials. 2014;21:445-52.

[80] Erden A, Bilgin S. Role of impurities in electric discharge machining. Proceedings of the Twenty-First International Machine Tool Design and Research Conference: Springer; 1981. p. 345-50.

[81] Jeswani M. Effect of the addition of graphite powder to kerosene used as the dielectric fluid in electrical discharge machining. Wear. 1981;70:133-9.

[82] Narumiya H, Mohri N, Saito N, Ootake H, Tsunekawa Y, Takawashi T, et al. EDM by powder suspended working fluid. Proceedings of 9th ISEM1989.

[83] YAN BH, CHEN SL. Characteristics of SKD11 by complex process of electricaldischarge machining using liquid suspended with alumina powder. 1994.

[84] Tzeng Y-F, Lee C-Y. Effects of powder characteristics on electrodischarge machining efficiency. The International Journal of Advanced Manufacturing Technology. 2001;17:586-92.

[85] Chow H-M, Yang L-D, Lin C-T, Chen Y-F. The use of SiC powder in water as dielectric for micro-slit EDM machining. Journal of Materials Processing Technology. 2008;195:160-70.

[86] Furutani K, Sato H, Suzuki M. Influence of electrical conditions on performance of electrical discharge machining with powder suspended in working oil for titanium carbide deposition process. The International Journal of Advanced Manufacturing Technology. 2009;40:1093-101.

[87] Syed KH, Palaniyandi K. Performance of electrical discharge machining using aluminium powder suspended distilled water. Turkish Journal of Engineering and Environmental Sciences. 2012;36:195-207.

[88] Muniu J, Nyaanga D, Ikua B, Gicharu S. Study on Effects of Powder-Mixed Dielectric Fluids on Electrical Discharge Machining Processes. International Journal of Engineering Research and Technology: ESRSA Publications; 2013.

[89] Garg R, Ojha K. Parametric optimization of PMEDM process with nickel micro powder suspended dielectric and varying triangular shapes electrodes on EN-19 steel. Journal of Engineering and Applied Sciences. 2011;6:152-6.

[90] Khedkar N K ST, Jatti V S. Material migration and surface improvement of OHNS die steel material by EDM method using tungsten powder-mixed dielectric. Wseas Transactions on Applied and Theoretical Mechanics. 2014;9:161-6. 
[91] Yan BH, Tsai HC, Huang FY. The effect in EDM of a dielectric of a urea solution in water on modifying the surface of titanium. International Journal of Machine Tools and Manufacture. 2005;45:194-200.

[92] Mai C, Hocheng H, Huang S. Advantages of carbon nanotubes in electrical discharge machining. The International Journal of Advanced Manufacturing Technology. 2012;59:111-7.

[93] Bhattacharya A, Batish A, Kumar N. Surface characterization and material migration during surface modification of die steels with silicon, graphite and tungsten powder in EDM process. Journal of Mechanical Science and Technology. 2013;27:133-40.

[94] Prihandana GS, Mahardika M, Hamdi M, Wong Y, Mitsui K. Effect of micropowder suspension and ultrasonic vibration of dielectric fluid in micro-EDM processes - Taguchi approach. International Journal of Machine Tools and Manufacture. 2009;49:1035-41.

[95] Cogun C, Özerkan B, Karacay T. An experimental investigation on the effect of powder mixed dielectric on machining performance in electric discharge machining. Proceedings of the Institution of Mechanical Engineers, Part B: Journal of Engineering Manufacture. 2006;220:1035-50.

[96] Rival R. Electrical discharge machining of titanium alloy using copper tungsten electrode with $\mathrm{SiC}$ powder suspension dielectric fluid. 2005.

[97] Peças P, Henriques E. Effect of the powder concentration and dielectric flow in the surface morphology in electrical discharge machining with powder-mixed dielectric (PMD-EDM). The International Journal of Advanced Manufacturing Technology. 2008;37:1120-32.

[98] Singh S, Yeh M-F. Optimization of abrasive powder mixed EDM of aluminum matrix composites with multiple responses using gray relational analysis. Journal of Materials Engineering and Performance. 2012;21:481-91.

[99] Ojha K, Garg R, Singh K. An investigation into the effect of nickel micro powder suspended dielectric and varying triangular shape electrodes on EDM performance measures of EN-19 steel. International Journal of Mechatronics and Manufacturing Systems. 2012;5:66-92.

[100] Jahan M, Rahman M, Wong Y. Modelling and experimental investigation on the effect of nanopowder-mixed dielectric in micro-electrodischarge machining of tungsten carbide. Proceedings of the Institution of Mechanical Engineers, Part B: Journal of Engineering Manufacture. 2010;224:1725-39.

[101] Prihandana GS, Sriani T, Mahardika M. Improvement of machining time in micro-EDM with workpiece vibration and graphite powder mixed in dielectric fluid. Indian Journal of Engineering \& Materials Sciences. 2012;19:375-8.

[102] Tseng K-H, Lee H-L, Liao C-Y, Chen K-C, Lin H-S. Rapid and efficient synthesis of silver nanofluid using electrical discharge machining. Journal of Nanomaterials. 2013;2013:1.

[103] A. Singh NG, P. Singh. Surface modification of EDM process using Carbon Nano tubes, A Review. International Journal of Engineering Research and Development. 2014;10:63-8.

[104] Khan MAR, Rahman MM, Kadirgama K, Bakar RA. Artificial neural network model for material removal rate of TI-15-3 in electrical discharge machining. Energy Education Science and Technology Part A: Energy Science and Research. 2012;29:1025-38. 
[105] Khan MAR, Rahman MM, Kadirgama K. Mathematical model and optimization of surface roughness during electrical discharge machining of Ti-5Al-2.5Sn with graphite electrode. Advanced Science Letters. 2012;15:367-72.

[106] Rahman MM, Khan MAR, Kadirgama K, Noor MM, Bakar RA. Experimental investigation into electrical discharge machining of stainless steel 304. Journal of Applied Sciences. 2011;11:549-54.

[107] Azraai MR, Priyandoko G, Yusof AR, Rashid MFFA. Parametric Optimization of Magneto-Rheological Fluid Damper Using Particle Swarm Optimization. International Journal of Automotive and Mechanical Engineering. 2015;11:25919.

[108] Meenu, Kumar S. Optimization of the Material Removal Rate in Turning of UDGFRP using the Particle Swarm Optimization Technique. International Journal of Automotive and Mechanical Engineering. 2013;8:1226-41.

[109] Kolli M, Kumar A. Effect of dielectric fluid with surfactant and graphite powder on Electrical Discharge Machining of titanium alloy using Taguchi method. Engineering Science and Technology, an International Journal. 2015;18:524-35.

[110] Dewangan S, Gangopadhyay S, Biswas C. Study of surface integrity and dimensional accuracy in EDM using Fuzzy TOPSIS and sensitivity analysis. Measurement. 2015;63:364-76.

[111] Sengottuvel P, Satishkumar S, Dinakaran D. Optimization of multiple characteristics of EDM parameters based on desirability approach and fuzzy modeling. Procedia Engineering. 2013;64:1069-78.

[112] Rahman MM, Kadirgama K. Material removal rate and surface roughness on grinding of ductile cast iron using minimum quantity lubrication. International Journal of Automotive and Mechanical Engineering. 2015;11:2471-83.

[113] Ashikur Rahman Khan M, Rahman MM, Kadirgama K, Ismail AR. RSM model to evaluate material removal rate in EDM of Ti-5Al-2.5Sn using graphite electrode. IOP Conference Series. 2012; 36(1): 1-8.

[114] Rahman MM, Khan MAR, Kadirgama K, Noor MM, Bakar RA. Mathematical modeling of material removal rate for Ti-5Al-2.5Sn through EDM process: A surface response method. Advances in Control, Chemical Engineering, Civil Engineering and Mechanical Engineering. 2010. p. 34-7.

[115] Rahman MM, Khan MAR, Kadirgama K, Noor MM, Bakar RA. Modeling of material removal on machining of Ti-6Al-4V through EDM using copper tungsten electrode and positive polarity. World Academy of Science, Engineering and Technology. 2010;71:576-81.

[116] Dewangan S, Gangopadhyay S, Biswas CK. Multi-response optimization of surface integrity characteristics of EDM process using grey-fuzzy logic-based hybrid approach. Engineering Science and Technology, an International Journal. 2015;18:361-8.

[117] Chiang K-T, Chang F-P, Tsai D-C. Modeling and analysis of the rapidly resolidified layer of $\mathrm{SG}$ cast iron in the EDM process through the response surface methodology. Journal of Materials Processing Technology. 2007;182:525-33.

[118] Sivasankar S JR, Kunhahamed P K. Performance study of tool materials and optimisation of pulse duration on EDM of zirconium di boride. International Journal of Machining and Machinability of Materials. 2013;14:123-41.

[119] Singh B, Kumar J, Kumar S. Investigating the influence of process parameters of ZNC EDM on machinability of A6061/10\% SiC composite. Advances in Materials Science and Engineering. 2013;2013. 
[120] Agrawal A, Dubey AK, Shrivastava PK. Modeling and optimization of tool wear rate in powder mixed EDM of MMC. 2nd International Conference on Mechanical and Robotics Engineering. 2013, p. 17-8.

[121] Kanagarajan D, Karthikeyan R, Palanikumar K, Davim JP. Optimization of electrical discharge machining characteristics of WC/Co composites using nondominated sorting genetic algorithm (NSGA-II). The International Journal of Advanced Manufacturing Technology. 2008;36:1124-32.

[122] Jung JH, Kwon WT. Optimization of EDM process for multiple performance characteristics using Taguchi method and Grey relational analysis. Journal of Mechanical Science and Technology. 2010;24:1083-90. 